\section{(2) OPEN ACCESS}

\title{
Disease understanding in patients newly diagnosed with atrial fibrillation
}

\author{
Brystana G Kaufman, ${ }^{1}$ Sunghee Kim, ${ }^{1}$ Karen Pieper, ${ }^{1}$ Larry A Allen, ${ }^{2}$ Bernard J Gersh, ${ }^{3}$ \\ Gerald V Naccarelli, ${ }^{4}$ Michael D Ezekowitz, ${ }^{5}$ Gregg C Fonarow, ${ }^{6}$ Kenneth W Mahaffey, \\ Daniel E Singer, ${ }^{8}$ Paul S Chan, ${ }^{9}$ James V Freeman, ${ }^{10}$ Jack Ansell, ${ }^{11}$ Peter R Kowey, ${ }^{5,12}$ \\ James A Rieffel, ${ }^{13}$ Jonathan Piccini, ${ }^{1}$ Eric Peterson, ${ }^{1}$ Emily C O'Brien ${ }^{1}$
}

\begin{abstract}
- Additional material is published online only. To view please visit the journal online (http://dx.doi.org/10.1136/ heartjnl-2017-311800).
\end{abstract}

For numbered affiliations see end of article.

\section{Correspondence to}

Brystana G Kaufman, Duke Clinical Research Institute, 2400 Pratt Street, 8th Floor \#8485, Durham, NC 27705, USA; brystana.kaufman@duke.edu

Received 4 May 2017 Revised 7 July 2017 Accepted 12 July 2017 Published Online First 27 September 2017

\section{Linked}

- http://dx.doi.org/10.1136/ heartjnl-2017-312124

Check for updates

To cite: Kaufman BG, Kim S, Pieper K, et al. Heart 2018;104:494-501.

\section{ABSTRACT}

Objective To describe self-reported disease understanding for newly diagnosed patients with atrial fibrillation (AF) and assess (1) how disease understanding changes over the first 6 months after diagnosis and (2) the relationship between patient understanding of therapies at baseline and treatment receipt at 6 months among treatment-naïve patients. Methods We analysed survey data from SATELLITE (Survey of Patient Knowledge and Personal Priorities for Treatment), a substudy of patients with new-onset AF enrolled in the national Outcomes Registry for Better Informed Treatment of Atrial Fibrillation (ORBIT) II registry across 56 US sites. Patients were surveyed at the baseline and 6-month follow-up clinic visits using Likert scales.

Results Among 1004 baseline survey responses, patients' confidence in their understanding of rhythm control, ablation, anticoagulation and cardioversion was suboptimal, with 'high' understanding ranging from $8.5 \%$ for left atrial appendage closure to $71.3 \%$ for rhythm therapy. Of medical history and demographic factors, education level was the strongest predictor of reporting 'high' disease understanding. Among the 786 patients with 6-month survey data, significant increases in the proportion reporting high understanding were observed $(p<0.05)$ only for warfarin and direct oral anticoagulants (DOACs). With the exception of ablation, high understanding for a given therapeutic option was not associated with increased use of that therapy at 6 months.

Conclusions About half of patients with new-onset AF understood the benefits of oral anticoagulant at the time of diagnosis and understanding improved over the first 6 months. However, understanding of AF treatment remains suboptimal at 6 months. Our results suggest a need for ongoing patient education.

Clinical trial registration Clinicaltrials.gov. Identifier: NCT01701817.

\section{INTRODUCTION}

Atrial fibrillation (AF) is the most common sustained arrhythmia and is associated with high mortality and morbidity. ${ }^{1} 2$ Although oral anticoagulation (OAC) has been shown to reduce stroke risk by two-thirds among patients with AF, approximately half of patients with AF and risk factors for stroke do not receive this treatment, and of those treated, many discontinue anticoagulation. ${ }^{3} 4$ Patients' confidence in their knowledge of available pharmacological and non-pharmacological therapeutic therapies for AF is essential to shared medical decision making and long-term medication adherence. Yet, there is a paucity of data regarding the extent to which patients newly diagnosed with AF in routine community practice feel they understand their treatment options and how this perception evolves over time.

Patients may have limited knowledge of the risks and therapeutic benefits associated with a diagnosis of $\mathrm{AF}^{5-7}$ and evidence suggests that patients' lack of knowledge surrounding their condition and treatment options presents a key barrier to the use of medications and adherence to recommendations. ${ }^{89}$ Some information is available via the internet and other public sources; however, the potential for misinformation from internet sources may adversely impact patient compliance. ${ }^{10-12}$ Interventions providing information about the need for warfarin, the risks and benefits associated with OAC therapy, potential interactions and the importance of monitoring international normalised ratio significantly improves time in therapeutic range in patients with AF initiating warfarin during the first 6 months. ${ }^{13}$ The treatment options for AF have become more complex over the past decade as additional therapeutic options are introduced including direct oral anticoagulants (DOACs), such as dabigatran, rivaroxaban, edoxaban and apixaban. ${ }^{14}$

In addition to actual knowledge, patients' confidence in their disease understanding is associated with self-efficacy and health literacy, which are prerequisite for changing patient behaviour. ${ }^{15} 16$ Understanding how patients' perceived knowledge of AF therapeutic options impacts treatment decisions may inform strategies to increase initiation and adherence to AF treatment. To meet this need, a survey was administered to participants of SATELLITE (Survey of Patient Knowledge and Personal Priorities for Treatment), a substudy of the national Outcomes Registry for Better Informed Treatment of Atrial Fibrillation (ORBIT) II registry, to collect data on patients' self-reported risk perception as well as the patient's confidence in their understanding of the role, options and benefits of existing and novel AF therapies. ${ }^{17}$ The goal of this study was to describe the level of understanding for newly diagnosed patients with $\mathrm{AF}$ and assess how patient 
understanding changes over the first 6 months for patients newly diagnosed with AF. Finally, we explored the relationship between patient understanding of therapeutic options at baseline and treatment rates at 6 months.

\section{METHODS}

\section{Design and setting}

The ORBIT-AF study, the largest outpatient registry of patients with AF in the USA includes two prospective outpatient disease registries. ${ }^{18}$ ORBIT I assessed treatment and outcomes in patients with incident or prevalent AF across 176 sites; ORBIT II included patients across 56 sites who were aged 21 years or older and diagnosed within the 6 months preceding the baseline visit or patients with $\mathrm{AF}$ who had initiation or transition to a factor Xa inhibitor or a direct thrombin inhibitor within the preceding 3 months. ${ }^{17} 19$ ORBIT II excluded patients with atrial flutter only, anticipated life expectancy less than 6 months, short lasting AF secondary to a reversible condition (eg, hyperthyroidism, pulmonary embolism and postcardiothoracic surgery), participation in a randomised trial of anticoagulation for $\mathrm{AF}$ at the time of enrolment or enrolment in the ORBIT-I Registry.

This analysis used data from the SATELLITE substudy, which surveyed a subset of patients participating in the ORBIT II registry. Only patients with an AF diagnosis within 6 months of enrolment and the ability to complete baseline and follow-up surveys in English were included in SATELLITE. Of 13415 patients enrolled in ORBIT II, 1004 participated in the SATELLITE substudy. A representative sample of cardiology, electrophysiology and primary care practices were selected for SATELLITE participation based on quality of registry data. Each site enrolled a convenience sample of patients meeting eligibility criteria until the 1000 patient enrolment target was reached. All Survey of Patient Knowledge and Personal Priorities for Treatment (SATELLITE) study participants gave written informed consent before enrolment. The Duke Institutional Review Board (IRB) approved the ORBIT II Registry, and all participating sites obtained approval from local IRBs before consenting.

Data collection for ORBIT II occurs at 6-month intervals over 2 years and includes demographics, medical history, cardiovascular risk factors, treatment strategies, clinical events and provider information. In addition, SATELLITE patients completed self-administered paper surveys at the baseline visit (12 March 2015-30 September 2016) and a follow-up survey at the 6-month clinic visit.

\section{Measures}

Survey questions were developed and refined by a panel of cardiologists, epidemiologists and electrophysiologists with subject matter expertise and experience conducting observational research in AF populations. Content validity was evaluated and confirmed by ORBIT-AF principal investigators. The scale was pilot-tested by 10 non-clinicians for readability and comprehension prior to deployment. This testing resulted in combination of several questions for parsimony and minor edits in question stem wording for clarity.

The survey assessed self-reported understanding of three disease concepts from the patient perspective using Likert scales: AF understanding, stroke risk understanding and understanding of therapeutic options, including rhythm control, ablation, warfarin, DOACs and cardioversion. General AF and stroke risk understanding were only assessed at baseline, while the understanding of therapeutic options was assessed at baseline and at 6 months.

In order to compare responses at baseline and at 6 months, the five response categories were used to define three levels of understanding for each question as shown in table 1. For questions with response categories strongly agree to strongly disagree, high understanding was defined as strongly or somewhat agree; neutral understanding was defined as a response of neutral; and low understanding was defined as a response of somewhat or strongly disagree. High understanding of stroke risk was defined a response of somewhat or strongly agree to the question 'The major risk of atrial fibrillation is stroke'. For questions with response categories completely understand to never heard of the therapy, high understanding was defined as a response of completely or mostly understand; low understanding was defined as a response of somewhat understand or understand very little; and no understanding was defined as never heard of the therapy.

$\mathrm{AF}$ treatment was defined using the forms completed by the sites at baseline and 6 months. For each time period, use of OACs was defined as use of warfarin, dabigatran, rivaroxaban, apixaban or edoxaban; rhythm control was defined as use of any

Table 1 SATELLITE survey questions and response categories

\begin{tabular}{|c|c|c|c|c|c|}
\hline Understanding of AF & High understanding & & $\begin{array}{l}\text { Moderate } \\
\text { understanding }\end{array}$ & Low understanding & \\
\hline I feel I understand what atrial fibrillation is. * & Strongly agree & Somewhat agree & Neutral & Somewhat disagree & Strongly disagree \\
\hline The major risk of atrial fibrillation is stroke. ${ }^{*}$ & Strongly agree & Somewhat agree & Neutral & Somewhat disagree & Strongly disagree \\
\hline \multicolumn{6}{|l|}{ Understanding of therapeutic options } \\
\hline $\begin{array}{l}\text { I understand the role of (rhythm control/ } \\
\text { ablation) in the treatment of AF. }\end{array}$ & Strongly agree & Somewhat agree & Neutral & Somewhat disagree & Strongly disagree \\
\hline $\begin{array}{l}\text { I understand the role of blood thinners in the } \\
\text { treatment of AF. }\end{array}$ & Strongly agree & Somewhat agree & Neutral & Somewhat disagree & Strongly disagree \\
\hline $\begin{array}{l}\text { I understand the various options for blood } \\
\text { thinners in the treatment of } \mathrm{AF}^{*}\end{array}$ & Strongly agree & Somewhat agree & Neutral & Somewhat disagree & Strongly disagree \\
\hline Understanding of therapeutic benefits & High understanding & & Low understanding & & No understanding \\
\hline $\begin{array}{l}\text { How well would you say you understand the } \\
\text { benefits of using the following therapies for } \\
\text { AF.t }\end{array}$ & Completely understand & Mostly understand & $\begin{array}{l}\text { Somewhat } \\
\text { understand }\end{array}$ & Understand very little & $\begin{array}{l}\text { Never heard of the } \\
\text { therapy }\end{array}$ \\
\hline
\end{tabular}

*Data collected at baseline only.

†Therapies included: warfarin/direct oral anticoagulants/left atrial appendage closure/cardioversion.

$\mathrm{AF}$, atrial fibrillation. 
antiarrhythmic medication; cardioversion was defined as any cardioversion procedure; and ablation was defined as utilisation of a catheter ablation for AF, specifically pulmonary vein isolation (PVI).

\section{Analysis}

Due to small sample sizes, the five response categories were collapsed into three levels of understanding for assessment of the change in understanding from baseline to 6 months. To test agreement between baseline and 6-month responses, weighted kappa statistics with 95\% CIs were generated for each outcome, with kappa $<0.2$ indicating poor agreement/substantial change, $0.21-0.4$ indicating fair agreement/moderate change, $0.41-0.6$ indicating moderate agreement/little change and $>0.6$ indicating good agreement/very little change. For the presentation in figures, the three levels of understanding were collapsed into two for the assessment of agreement between baseline and 6-month responses and the relationship between understanding at baseline and treatment at 6 months. Agreement between time points for binary measures was assessed with the McNemar test. To avoid bias due to the impact of treatment at baseline on understanding at baseline, the relationship between patient understanding and treatment at 6 months was assessed only for the subset who have not had a given treatment or procedure at baseline. SK had full access to all the data in the study and takes responsibility for its integrity and the data analysis.

\section{RESULTS}

Among 1004 patients with baseline survey data, 86\% used OACs, 34\% used antiarrhythmic medications and 20\% had catheter ablation of AF at baseline. Among the 786 completing the 6-month survey, the median age was 69.0 years (IQR 63.0-76.0) and $92.1 \%$ (724 of 786) were white. Compared with the SATELLITE participants with baseline data only, those completing the survey at 6 months were older, more likely to smoke or have hypertension, more likely to have prior cardioversion and had a higher risk of stroke as measured by the $\mathrm{CHA}_{2} \mathrm{DS}_{2}$-Vasc score.

\section{Self-reported patient understanding at baseline}

At the baseline visit, $81.8 \%$ of SATELLITE patients reported high understanding of AF with a response of somewhat or strongly agree following the statement 'I feel I understand what Atrial Fibrillation is'. Nearly 9 in 10 patients (87.2\%) reported a high understanding that the major risk of AF is stroke. Relative to those with less understanding, patients with a high understanding that the major risk of AF is stroke were more likely to be young, have a college education and have lower bleeding risk as measured by the ORBIT score (older age, anaemia, bleeding history, kidney function and treatment with antiplatelet ${ }^{20}$ and Anticoagulation and Risk Factors in Atrial Fibrillation (ATRIA) score (older age, anaemia, severe renal disease, bleeding history and hypertension $)^{21} 22$; however, there was little difference in the prevalence of comorbidities such as diabetes and hypertension (table 2). The proportion of patients with a high understanding of stroke risk was similar across gender and census region. In the adjusted analysis including patient demographics and medical history, education level was the only significant predictor of understanding with the odds of reporting high understanding cut by half for patients without a college degree (table 3).

Baseline understanding of therapeutic options was variable, ranging from $8.5 \%$ to $71.3 \%$ reporting a high understanding of the benefits for left atrial appendage closure and role of rhythm control, respectively. About half reported a high understanding of the benefits of warfarin and DOACs $(45.6 \%$ and $50.0 \%$, respectively). Patients receiving care from cardiologists and electrophysiologists were more likely to report a high understanding of the various therapies at baseline than patients receiving care from a primary care physician; however, due to the small numbers of patients receiving care from primary care physicians, the statistical significance of this difference was not assessed. Full results for the baseline and follow-up surveys are presented in online supplementary material.

\section{Changes in patient understanding of AF from baseline to 6 months}

Moderate change (kappa $<0.4$ ) in patient understanding of therapeutic options from baseline to 6-month follow-up visit occurred for all therapies except cardioversion (kappa $=0.42, \mathrm{CI}=0.36$ to 0.47 ) (table 4). For example, about half of those who reported low or moderate understanding of the role of rhythm control therapies at baseline reported high understanding at 6 months (50.0\% and 53.9\%, respectively). About one-third of patients reporting low or moderate understanding of the role of ablation therapies at baseline reported high understanding at 6 months (32.8\% and $31.4 \%$, respectively). Of patients reporting low or no understanding of the benefits of DOACs at the baseline visit, $59.1 \%$ and $32.1 \%$ improved to high understanding at 6 months, respectively. Improvement in understanding of warfarin benefit was similar. After 6 months, two-thirds of patients report low understanding of the benefits of LAAC (63.6\%), one-third report low understanding of the role of ablation (37.1\%) and one quarter report low understanding of the role of rhythm control (25.8\%).

Though perceived understanding improved between the baseline and 6-month visit for some patients, others reported less understanding at the 6-month visit than at baseline. Overall, the net increase in the proportion reporting high understanding was significant for warfarin $(\mathrm{p}<0.0001)$ and DOACs $(\mathrm{p}<0.0001)$ from $45.6 \%$ and $50.0 \%$ at baseline to $59.1 \%$ and $68.7 \%$ at 6 months, respectively (figure 1 ), but not for rhythm control, ablation or cardioversion.

\section{Relationship between patient understanding and treatment}

At the baseline visit, over $80 \%$ of SATELLITE patients used OACs, two-thirds used rhythm control and less than a quarter had a PVI. Use of a treatment at baseline was positively associated with baseline understanding of the role of that therapy $(\mathrm{p}<0.001)$. For example, over $90 \%$ of patients using an OAC at baseline reported a high understanding of the role of blood thinners at baseline as compared with less than $80 \%$ among non-users. Patients reporting a high baseline understanding of ablation are more likely to receive PVI; however, patients' understanding of OAC or rhythm control was not associated with initiation of OAC or rhythm control, respectively, within 6 months (figure 2). Patients with high understanding of the benefits $(p=0.0005)$ of ablation and options for ablation $(p=0.0093)$ at baseline were more likely to initiate PVI within 6 months $(n=799)$. Improved perceived understanding of therapeutic options at baseline was not associated with increased initiation of blood thinners including DOACs and warfarin $(\mathrm{n}=132)$ or rhythm control $(n=577)$ within 6 months.

\section{DISCUSSION}

Among patients with new-onset AF, patients' confidence in their understanding of rhythm control, ablation, anticoagulation and cardioversion was suboptimal, with 30\%-60\% of 
Table 2 SATELLITE patient characteristics by self-reported understanding of atrial fibrillation stroke risk at baseline

\begin{tabular}{|c|c|c|c|c|}
\hline & All & High understanding & Neutral or low understanding & \\
\hline & $\mathrm{n}=988$ & $\mathrm{n}=862$ & $n=126$ & $\mathrm{p}$ Value \\
\hline \multicolumn{5}{|l|}{ Demographics (n (\%)) } \\
\hline Age, median (IQR) & $68.0(61.0-76.0)$ & $68.0(60.0-76.0)$ & $70.0(63.0-78.0)$ & 0.0202 \\
\hline Male & $572(57.9)$ & $497(57.7)$ & $75(59.5)$ & 0.6919 \\
\hline College graduate & $336(34.0)$ & $300(34.8)$ & $36(28.6)$ & 0.0003 \\
\hline \multicolumn{5}{|l|}{ Risk factors (n (\%)) } \\
\hline Congestive heart failure & $208(21.1)$ & $175(20.3)$ & $33(26.2)$ & 0.1301 \\
\hline Stroke & $44(4.5)$ & $42(4.9)$ & $2(1.6)$ & 0.0951 \\
\hline Prior Ml & $98(9.9)$ & $89(10.3)$ & $9(7.1)$ & 0.2646 \\
\hline Hypertension & $738(74.7)$ & $640(74.2)$ & $98(77.8)$ & 0.3946 \\
\hline Diabetes & $258(26.1)$ & $218(25.3)$ & $40(31.7)$ & 0.1235 \\
\hline COPD & $115(11.6)$ & $94(10.9)$ & $21(16.7)$ & 0.0597 \\
\hline Smoker & $493(49.9)$ & $425(49.3)$ & $68(54.0)$ & 0.3283 \\
\hline Obstructive sleep apnoea & $180(18.2)$ & $160(18.6)$ & $20(15.9)$ & 0.4655 \\
\hline Any prior cardioversions & $212(21.5)$ & $194(22.5)$ & $18(14.3)$ & 0.0359 \\
\hline \multicolumn{5}{|l|}{$\mathrm{CHA} \square \mathrm{DS} \square$-VASC score (n (\%)) } \\
\hline Low: 0 & $53(5.4 \%)$ & $48(5.6 \%)$ & $5(4.0 \%)$ & 0.3258 \\
\hline Medium: 1 & $143(14.5 \%)$ & $127(14.7 \%)$ & $16(12.7 \%)$ & - \\
\hline High: 2+ & $792(80.2)$ & $687(79.7 \%)$ & $105(83.3 \%)$ & - \\
\hline \multicolumn{5}{|l|}{ ORBIT (n (\%)) } \\
\hline Low: 0-2 & $701(71.0)$ & $625(72.5)$ & $76(60.3)$ & 0.0084 \\
\hline Moderate: 3 & $113(11.4)$ & $90(10.4)$ & $23(18.3)$ & - \\
\hline High: >3 & $109(11.0)$ & $92(10.7)$ & $17(13.5)$ & - \\
\hline \multicolumn{5}{|l|}{ ATRIA score $(\mathrm{n}(\%))$} \\
\hline 0 & $156(15.8)$ & $141(16.4)$ & $15(11.9)$ & 0.0152 \\
\hline 1 & $381(38.6)$ & $340(39.4)$ & $41(32.5)$ & - \\
\hline 2 & $53(5.4)$ & $46(5.3)$ & 7 (5.6) & - \\
\hline$\geq 3$ & $398(40.3)$ & $335(38.9)$ & $63(50.0)$ & - \\
\hline
\end{tabular}

'High Understanding' of stroke risk was defined a response of Somewhat or Strongly agree to the question 'The major risk of atrial fibrillation is stroke'.

ATRIA, Anticoagulation and Risk Factors in Atrial Fibrillation; COPD, chronic obstructive pulmonary disease; MI, myocardial infarction; ORBIT, Outcomes Registry for Better Informed Treatment of Atrial Fibrillation.

Table 3 SATELLITE patient characteristics associated with selfreported high understanding of atrial fibrillation stroke risk

\begin{tabular}{|c|c|c|}
\hline $\begin{array}{l}\text { Patient characteristics } \\
(n=897)\end{array}$ & $\begin{array}{l}\text { Unadjusted OR } \\
(95 \% \mathrm{Cl})\end{array}$ & Adjusted OR $(95 \% \mathrm{Cl})$ \\
\hline \multicolumn{3}{|l|}{ Demographics } \\
\hline Age (5 years) & $0.91(0.82 \text { to } 1.00)^{*}$ & 0.91 (0.80 to 1.03$)$ \\
\hline Female & $1.37(0.89$ to 2.10$)$ & 1.61 (0.99 to 2.62$)$ \\
\hline White & $1.27(0.64$ to 2.53$)$ & 1.33 (0.664 to 2.75$)$ \\
\hline No college degree & $0.47(0.29 \text { to } 0.74)^{*}$ & $0.48(0.30 \text { to } 0.78)^{\star}$ \\
\hline \multicolumn{3}{|l|}{ Medical history } \\
\hline CHA $\square \mathrm{DS} \square$-VASC score $\geq 2$ & $0.92(0.53$ to 1.61$)$ & 1.47 (0.646 to 3.26$)$ \\
\hline ORBIT score $\geq 3$ & $0.53(0.33 \text { to } 0.83)^{*}$ & $0.67(0.40$ to 1.13$)$ \\
\hline Congestive heart failure & 0.73 (0.45 to 1.20$)$ & 0.79 (0.46 to 1.37$)$ \\
\hline Prior myocardial infarction & $1.17(0.55$ to 2.48$)$ & 1.78 (0.78 to 4.04$)$ \\
\hline Hypertension & 0.81 (0.49 to 1.35$)$ & 0.90 (0.49 to 1.64$)$ \\
\hline Diabetes & $0.80(0.51$ to 1.26$)$ & 0.94 (0.536 to 1.58$)$ \\
\hline COPD & 0.65 (0.36 to 1.18$)$ & 0.80 (0.43 to 1.51$)$ \\
\hline Smoker & 0.72 (0.47 to 1.12 ) & 0.84 (0.52 to 1.33$)$ \\
\hline Any prior cardioversion & $1.71(0.95$ to 3.07$)$ & 1.59 (0.87 to 2.91$)$ \\
\hline \\
\hline \multicolumn{3}{|c|}{$\begin{array}{l}\text { 'High Understanding' of stroke risk was defined a response of Somewhat or } \\
\text { Strongly agree to the question 'The major risk of atrial fibrillation is stroke'. } \\
\text { AF, atrial fibrillation; COPD, chronic obstructive pulmonary disease; ORBIT, } \\
\text { Outcomes Registry for Better Informed Treatment of Atrial Fibrillation. }\end{array}$} \\
\hline
\end{tabular}

Kaufman BG, et al. Heart 2018;104:494-501. doi:10.1136/heartjnl-2017-311800 patients reporting uncertainty about the role, benefits and options for these therapies at both the baseline and follow-up visits. Although understanding of DOACs and warfarin benefits improved over the first 6 months from diagnosis, routine care in community practices did not result in improved patient understanding of other treatment options. With the exception of ablation, patient reported understanding of therapeutic benefits and options was not associated with initiation of treatment within the first 6 months.

The finding that patients' perceived understanding of AF is suboptimal is consistent with prior research demonstrating gaps in knowledge. ${ }^{12} 2324$ However, only 13\% of SATELLITE patients were unsure whether stroke is a risk of AF, compared with over $30 \%$ in prior studies. ${ }^{25}$ This difference is likely because this study specifically sought to assess understanding from the patient's perspective, and patients may have overestimated their understanding of AF and stroke risk. Studies comparing selfrated knowledge to actual knowledge of AF have found gaps in knowledge relative to perceived understanding, although there was a correlation between the two measures. ${ }^{26}$

The inconsistent association between perceived treatment understanding and uptake in this study contrasts with evidence suggesting that patients' understanding influences uptake of OACs. ${ }^{89}$ One explanation may be the exclusion of prevalent OAC users at baseline. The $14 \%$ of SATELLITE patients not on OACs at baseline may be more likely to have a contraindication or a strong personal preference preventing OAC use. However, 
Table 4 SATELLITE patient understanding of atrial fibrillation therapies at baseline and at 6 months

\begin{tabular}{|c|c|c|c|c|}
\hline \multirow{2}{*}{$\begin{array}{l}\text { Survey question }(\mathrm{N}) \\
\text { Panel A: role of rhythm control }(n=589)\end{array}$} & \multirow{2}{*}{$\begin{array}{l}\text { Understanding at baseline } \\
\text { All }\end{array}$} & \multicolumn{3}{|c|}{ Understanding at 6-month follow-up } \\
\hline & & High understanding & Moderate understanding & Low understanding \\
\hline Baseline understanding & $\%$ & $\%$ & $\%$ & $\%$ \\
\hline High understanding & 71.3 & 79.8 & 12.6 & 7.6 \\
\hline Moderate understanding & 15.4 & 53.9 & 27.5 & 18.7 \\
\hline Low understanding & 13.2 & 50.0 & 19.2 & 30.8 \\
\hline \multicolumn{5}{|l|}{ Weighted kappa $=0.26(0.18,0.33)$} \\
\hline Panel B: options for rhythm control ( $n=581)$ & All & High understanding & Moderate understanding & Low understanding \\
\hline Baseline understanding & $\%$ & $\%$ & $\%$ & $\%$ \\
\hline High understanding & 44.8 & 63.5 & 19.2 & 17.3 \\
\hline Moderate understanding & 26.9 & 43.6 & 30.8 & 25.6 \\
\hline Low understanding & 28.4 & 28.5 & 24.9 & 46.7 \\
\hline \multicolumn{5}{|l|}{ Weighted kappa $=0.27(0.20,0.34)$} \\
\hline Panel C: role of ablation $(n=546)$ & All & High understanding & Moderate understanding & Low understanding \\
\hline Baseline understanding & $\%$ & $\%$ & $\%$ & $\%$ \\
\hline High understanding & 44.3 & 66.1 & 12.4 & 21.5 \\
\hline Moderate understanding & 22.2 & 31.4 & 36.4 & 32.2 \\
\hline Low understanding & 33.5 & 32.8 & 15.9 & 51.4 \\
\hline \multicolumn{5}{|l|}{ Weighted kappa $=0.30(0.23,0.37)$} \\
\hline Panel D: options for ablation ( $n=578)$ & All & High understanding & Moderate understanding & Low understanding \\
\hline Baseline understanding & $\%$ & $\%$ & $\%$ & $\%$ \\
\hline High understanding & 35.3 & 55.4 & 22.1 & 22.6 \\
\hline Moderate understanding & 25.4 & 30.6 & 34.0 & 35.4 \\
\hline Low understanding & 39.3 & 22.9 & 19.4 & 57.7 \\
\hline \multicolumn{5}{|l|}{ Weighted kappa $=0.30(0.23,0.36)$} \\
\hline Panel E: benefits of cardioversions ( $n=743$ ) & All & High understanding & Low understanding & No understanding \\
\hline Baseline understanding & $\%$ & $\%$ & $\%$ & $\%$ \\
\hline High understanding & 47.1 & 78.9 & 16.6 & 4.6 \\
\hline Low understanding & 38.2 & 34.9 & 53.9 & 11.3 \\
\hline No understanding & 14.7 & 22.9 & 41.3 & 35.8 \\
\hline \multicolumn{5}{|l|}{ Weighted kappa $=0.42(0.36,0.47)$} \\
\hline Panel F: benefits of warfarin ( $n=724)$ & All & High understanding & Low understanding & No understanding \\
\hline Baseline understanding & $\%$ & $\%$ & $\%$ & $\%$ \\
\hline High understanding & 45.6 & 77.9 & 19.1 & 3.0 \\
\hline Low understanding & 41.4 & 47.0 & 49.0 & 4.0 \\
\hline No understanding & 13.0 & 31.9 & 44.7 & 23.4 \\
\hline \multicolumn{5}{|l|}{ Weighted kappa $=0.32(0.26,0.37)$} \\
\hline Panel G: benefits of DOACs ( $n=738)$ & All & High understanding & Low understanding & No understanding \\
\hline Baseline understanding & $\%$ & $\%$ & $\%$ & $\%$ \\
\hline High understanding & 50.0 & 84.0 & 14.6 & 1.4 \\
\hline Low understanding & 39.4 & 59.1 & 38.5 & 2.4 \\
\hline No understanding & 10.6 & 32.1 & 44.9 & 23.1 \\
\hline \multicolumn{5}{|l|}{ Weighted kappa $=0.30(0.24,0.36)$} \\
\hline Panel H: benefits of left atrial appendage closure $(n=734)$ & All & High understanding & Low understanding & No understanding \\
\hline Baseline understanding & $\%$ & $\%$ & $\%$ & $\%$ \\
\hline High understanding & 8.5 & 32.3 & 22.6 & 45.2 \\
\hline Low understanding & 25.3 & 13.4 & 41.9 & 44.6 \\
\hline No understanding & 66.2 & 6.0 & 20.8 & 73.3 \\
\hline Weighted kappa $=0.26(0.20,0.33)$ & & & & \\
\hline
\end{tabular}

patient understanding is likely to be a stronger indicator for uptake of procedures used more selectively, including cardioversion or ablation. For example, the association found between a high understanding of ablation and PVI within 6 months may be a result of electrophysiologists or proablation physicians introducing patients to ablation early in the disease trajectory relative to physicians with different preferences.
The similar baseline rates and increases in perceived understanding of warfarin and DOACs indicate that patients' access to information about the newer DOACs may be similar to access to information about warfarin. No systematic communication was required from physicians to educate patients about specific therapeutic options, and differences in physician preference and practice patterns likely played a role in the observed changes 


\section{Figure 1}

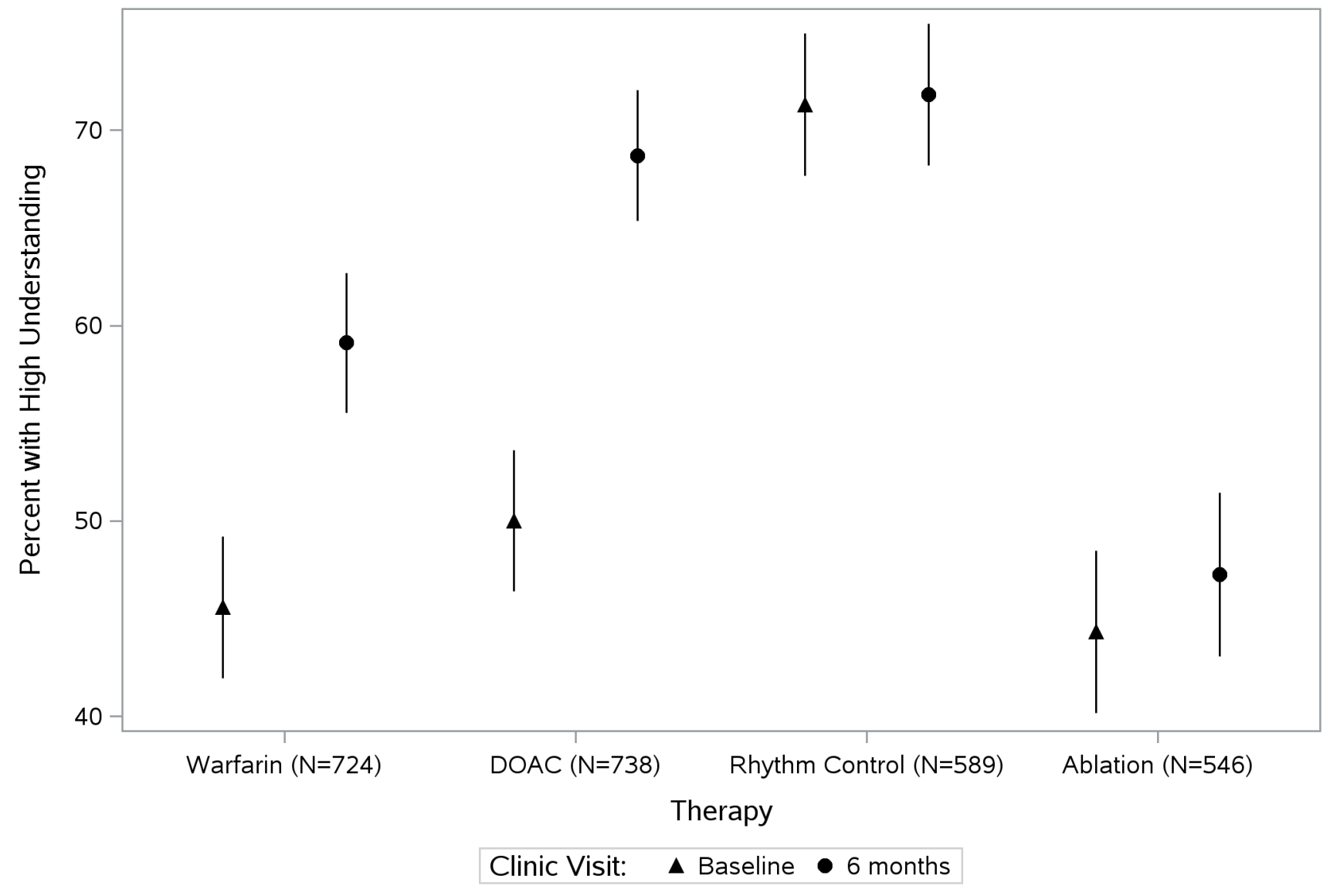

Figure 1 Proportion of SATELLITE patients with high understanding of atrial fibrillation therapies at baseline and at 6 months. Notes: high understanding was defined as a response of completely or mostly to the question 'How well would you say you understand the role (rhythm control, ablation) or benefits of using (warfarin, DOAC)'. DOAC, direct oral anticoagulant.

in patient understanding over the first 6 months. In addition, one quarter of SATELLITE patients reported their top source of information was the internet and other non-physician sources that may have contributed to the increase in knowledge of OACs following diagnosis. ${ }^{27}$

AF patients' lack of confidence in their understanding of AF represents an opportunity to improve outcomes with interventions targeting patient perceptions and health literacy, particularly among those with low educational attainment. Low health literacy is consistently associated with disease-related knowledge and self-efficacy, which are prerequisite to establishing behaviours necessary for effective self-management of AF. ${ }^{16}$ The integrated care approach to AF management includes components targeting health literacy and has reduced hospitalisation and mortality; for example, interventions including postdischarge management and an AF chronic care clinic improved outcomes relative to standard care. ${ }^{28-30}$

\section{Limitations}

The study was limited to participating sites and patients volunteering to complete the surveys, which may limit the external validity of these data. These results are based on self-reports of patient understanding and should be interpreted with more caution than validated measures of disease knowledge. This study describes patient's perception of disease understanding rather than demonstrated knowledge. The analysis of the relationship between understanding at baseline and treatment initiation was restricted to patients not on therapy at baseline, which resulted in a limited sample in which to assess OAC initiation due to the high rates of use at baseline. Finally, in this descriptive analysis, the associations between patient understanding and treatment decisions may be confounded by other factors, including physician practices, clinical presentation and patient socioeconomic factors.

\section{CONCLUSIONS}

Physician and patient factors that influence AF disease understanding and shared decision making should be a priority in future research. In routine community practice, patients' perceived understanding of AF therapeutic options is suboptimal at diagnosis and remains so at 6 months, suggesting a role for ongoing patient education. Future work should focus on elucidating specific factors contributing to low health literacy, such as socioeconomic status, multimorbidity and suboptimal patient-provider communication. Such knowledge could support development of targeted interventions to improve disease understanding and support better communication about stroke risk and available therapies in vulnerable patient populations. 


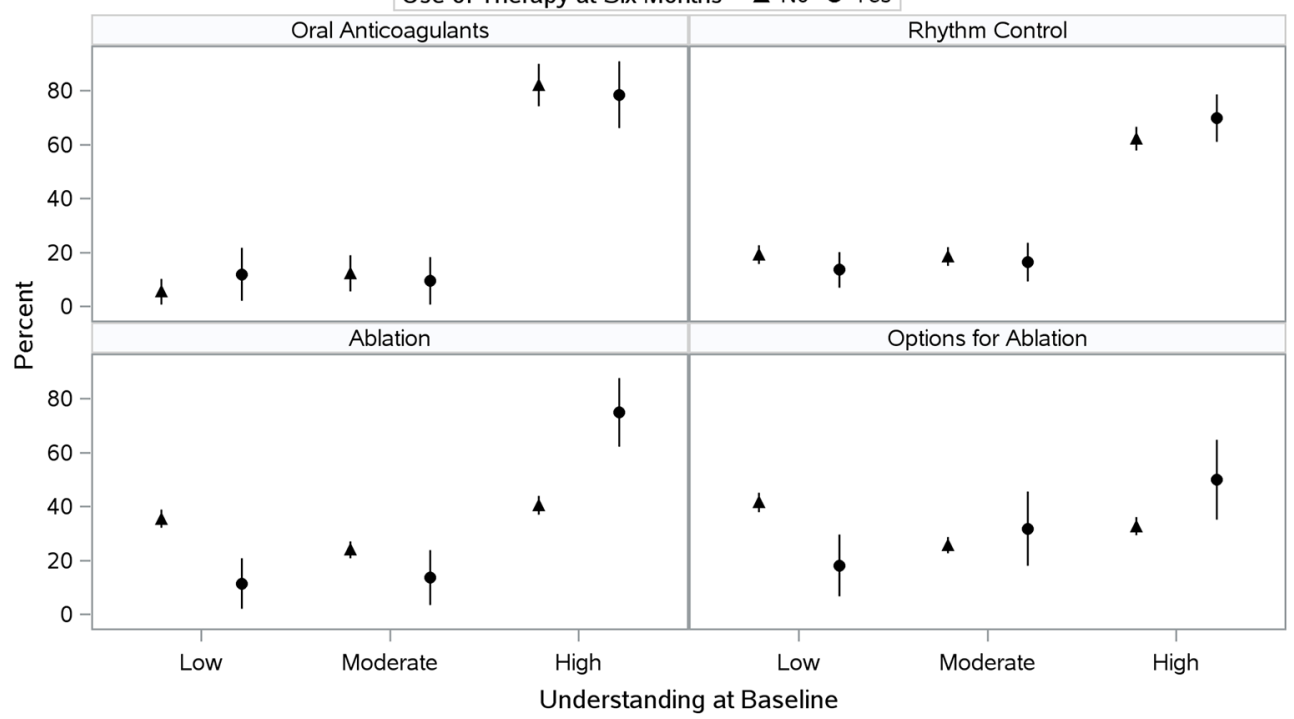

Oral Anticoagulants: Low $(N=10)$, Moderate $(N=15), \operatorname{High}(N=107)$

Rhythm Control: $\operatorname{Low}(\mathrm{N}=105)$, Moderate $(\mathrm{N}=105), \operatorname{High}(\mathrm{N}=367)$

Ablation: $\operatorname{Low}(\mathrm{N}=273)$, Moderate $(\mathrm{N}=187)$, $\operatorname{High}(\mathrm{N}=339)$

Options for Ablation: Low $(\mathrm{N}=322)$, Moderate $(\mathrm{N}=208)$, High $(\mathrm{N}=269)$

Figure 2 SATELLITE patient understanding of role or options for atrial fibrillation therapies at baseline and use of therapy at 6 months. Notes: the relationship between patient understanding and therapy at 6 months was assessed only for the subset of patients not on the treatment at baseline. Ablation therapy was defined as use of pulmonary vein isolation (PVI). Rhythm control therapy was defined as antiarrhythmic medication.

\section{Key messages}

\section{What is already known on this subject?}

Patients' confidence in their understanding of available pharmacological and non-pharmacological therapeutic therapies for atrial fibrillation is essential to shared medical decision making and long-term medication adherence.

\section{What might this study add?}

This study provides evidence regarding extent to which patients newly diagnosed with $\mathrm{AF}$ in routine community practice understand existing and novel therapeutic options, how this understanding evolves over time and the association with treatment initiation.

\section{How might this impact on clinical practice?}

In routine community practice, patient understanding of AF therapeutic options is suboptimal at baseline and remains so at 6 months, suggesting a role for ongoing patient education.

\section{Author affiliations}

Duke Clinical Research Institute, Durham, North Carolina, USA

2University of Colorado School of Medicine, Aurora, Colorado, USA

${ }^{3}$ Mayo Clinic, Rochester, New York, USA

${ }^{4}$ Penn State Hershey Heart and Vascular Institute, Hershey, Pennsylvania, USA

${ }^{5}$ Jefferson Medical College, Philadelphia, Pennsylvania, USA

${ }^{6}$ Division of Cardiology, University of California, Los Angeles, California, USA

${ }^{7}$ Stanford Center for Clinical Research, School of Medicine, Stanford, California, USA

${ }^{8}$ Harvard Medical School and Massachusetts General Hospital, Boston,

Massachusetts, USA

${ }^{9}$ Department of Cardiovascular Research, St. Luke's Mid America Heart Institute,

Kansas City, Missouri, USA

${ }^{10}$ Department of Medicine, Yale University School of Medicine, New Haven,

Connecticut, USA

${ }^{11}$ Hofstra Northwell School of Medicine, New York, New York, USA

${ }^{12}$ Lankenau Institute for Medical Research, Wynnewood, Pennsylvania, USA

${ }^{13}$ Columbia University, New York, New York, USA
Acknowledgements The authors would like to thank the staff and participants of the ORBIT-II AF registry and Tony Schibler for their important contributions to this work.

Contributors BGK, SK, KP and ECO: conception, analysis and interpretation of data. LAA, BJG, GVN, MDE, GCF, KWM, DES, PSC, JVF, JA, PRK, JAR, JP, EP and ECO: conception, acquisition and interpretation of data. All authors participated in critically revising the manuscript for important intellectual content, provided final approval of the version to be published and agree to be accountable for all aspects of the work in ensuring that questions related to the accuracy or integrity of any part of the work are appropriately investigated and resolved.

Competing interests BGK, SK and KP: None. LAA: consultancy from Novartis (significant) and Janssen. JP: significant research support from Boston Scientific, ResMed, ARCA Biopharma, St. Jude Medical Center, Gilead Sciences, Johnson\&Johnson, Spectranetics and Janssen and consultancies to Janssen (significant), Spectranetics (significant), Medtronic (significant), Forest Laboratories (modest), Pfizer (modest) and GlaxoSmithKline (modest). EP: significant research support from Eli Lilly \& Company, Daiichi Sankyo and Janssen. ECO: significant research grant from Janssen, BMS, Novartis and Pfizer. BJG: consultancies to Janssen Scientific Affairs (significant) and Cipla Limited Data Safety Monitoring Board (modest) for: Mount Sinai St. Lukes, Boston Scientific Corporation, Teva Pharmaceutical Industries, St. Jude Medical, Janssen Research \& Development, Baxter Healthcare Corporation, Thrombosis Research Institute, Duke Clinical Research Institute, Duke University, Kowa Research Institute and Cardiovascular Research Foundation. PRK: consultant to Johnson\&Johnson (significant). GCF: consultant to Janssen (modest). JAR: consultant and/or speaker's bureau for Boehringer-Ingelheim, Janssen (significant), Pfizer, BMS, Portola (modest) and Daiichi Sankyo. JVF: consultant to Janssen (modest) and salary support from the American College of Cardiology National Cardiovascular Data Registry. JA: consultancy/advisory board to Bristol-Myers Squibb; Pfizer; Janssen; Daiichi Sankyo; Boehringer Ingelheim; Instrumentation Laboratories; Perosphere; Roche Diagnostics. Equity in Perosphere. MDE: consultancies to Boehringer Ingelheim and Daiichi Sankyo (modest) and Bristol-Myers Squibb, Pfizer, Johnson\&Johnson and Janssen Scientific Affairs (significant). GVN: consultant/advisory board to Janssen, Daiichi Sankyo, GlaxoSmithKline, Astra Zeneca; research support from Janssen. PSC: funding from the NHLBI (1R01HL123980). DES: consultant/advisory board to Boehringer Ingelheim, Bristol-Myers Squibb, Merck, Johnson\&Johnson, Medtronic, Pfizer; research grants from Boehringer Ingelheim, Bristol-Myers Squibb and Medtronic. KWM: financial disclosures can be viewed at http://med.stanford.edu/ profiles/kenneth-mahaffey.

Ethics approval Duke Institutional Review Board.

Provenance and peer review Not commissioned; externally peer reviewed. 
Open Access This is an Open Access article distributed in accordance with the Creative Commons Attribution Non Commercial (CC BY-NC 4.0) license, which permits others to distribute, remix, adapt, build upon this work non-commercially, and license their derivative works on different terms, provided the original work is properly cited and the use is non-commercial. See: http://creativecommons.org/ licenses/by-nc/4.0/

(c) Article author(s) (or their employer(s) unless otherwise stated in the text of the article) 2018. All rights reserved. No commercial use is permitted unless otherwise expressly granted.

\section{REFERENCES}

1 Benjamin EJ, Wolf PA, D'Agostino RB, et al. Impact of atrial fibrillation on the risk of death: the Framingham Heart Study. Circulation 1998;98:946-52.

2 Wang TJ, Larson MG, Levy D, et al. Temporal relations of atrial fibrillation and congestive heart failure and their joint influence on mortality: the Framingham Heart Study. Circulation 2003;107:2920-5.

3 Piccini JP, Hernandez AF, Zhao X, et al. Quality of care for atrial fibrillation among patients hospitalized for heart failure. J Am Coll Cardiol 2009;54:1280-9.

4 Ogilvie IM, Newton N, Welner SA, et al. Underuse of oral anticoagulants in atrial fibrillation: a systematic review. Am J Med 2010;123:e634:638-45.

5 Aliot E, Breithardt G, Brugada J, et al. An international survey of physician and patient understanding, perception, and attitudes to atrial fibrillation and its contribution to cardiovascular disease morbidity and mortality. Europace 2010;12:626-33.

6 Dearborn JL, McCullough LD. Perception of risk and knowledge of risk factors in women at high risk for stroke. Stroke 2009;40:1181-6.

7 Lip GY, Kamath S, Jafri M, et al. Ethnic differences in patient perceptions of atrial fibrillation and anticoagulation therapy: the West Birmingham Atrial Fibrillation Project. Stroke 2002;33:238-42.

8 Tang EO, Lai CS, Lee KK, et al. Relationship between patients' warfarin knowledge and anticoagulation control. Ann Pharmacother 2003;37:34-9.

9 Lane DA, Ponsford J, Shelley A, et al. Patient knowledge and perceptions of atrial fibrillation and anticoagulant therapy: effects of an educational intervention programme. the West Birmingham Atrial Fibrillation Project. Int J Cardiol 2006;110:354-8.

10 Pandya E, Bajorek BV. Assessment of Web-based education resources informing patients about stroke prevention in atrial fibrillation. J Clin Pharm Ther 2016:41:667-76.

11 Vormfelde SV, Abu Abed M, Hua TD, et al. Educating orally anticoagulated patients in drug safety: a cluster-randomized study in general practice. Dtsch Arztebl Int 2014;111:607-14

12 Clarkesmith DE, Pattison HM, Lane DA. Educational and behavioural interventions for anticoagulant therapy in patients with atrial fibrillation. Cochrane Database Syst Rev 2013:Cd008600.

13 Clarkesmith DE, Pattison HM, Lip GY, et al. Educational intervention improves anticoagulation control in atrial fibrillation patients: the TREAT randomised trial. PLOS One 2013;8:e74037.

14 ea AW. Oral anticoagulant therapy: antithrombotic therapy and Prevention of Thrombosis. 9th ed: American College of Chest Physicians Evidence-Based Clinic., 2017. PubMed - NCBI.
15 Glanz K, Lewis FM, Rimers BK, et al. Research, and practice. San Francisco, CA: JosseyBass, 1990.

16 Mackey LM, Doody C, Werner EL, et al. Self-Management skills in Chronic Disease Management: what role does Health literacy have? Med Decis Making 2016;36:741-59.

17 Steinberg BA, Blanco RG, Ollis D, et al. ORBIT-AF Steering Committee Investigators. Outcomes Registry for Better Informed Treatment of Atrial Fibrillation II: rationale and design of the ORBIT-AF II registry. Am Heart J 2014;168:160-7.

18 Piccini JP, Fraulo ES, Ansell JE, et al. Outcomes registry for better informed treatment of atrial fibrillation: rationale and design of ORBIT-AF. Am Heart J 2011;162:e601:606-12.

19 O'Brien EC, Kim S, Thomas L, et al. Clinical characteristics, oral anticoagulation patterns, and outcomes of Medicaid Patients with Atrial Fibrillation: insights from the Outcomes Registry for Better Informed treatment of Atrial Fibrillation (ORBIT-AF I) Registry. J Am Heart Assoc 2016;5:e002721.

20 O'Brien EC, Simon DN, Thomas LE, et al. The ORBIT bleeding score: a simple bedside score to assess bleeding risk in atrial fibrillation. Eur Heart J 2015;36:ehv476-3264

21 Fang MC, Go AS, Chang Y, et al. A new risk scheme to predict warfarin-associated hemorrhage: the ATRIA (Anticoagulation and risk factors in Atrial Fibrillation) Study. J Am Coll Cardiol 2011;58:395-401.

22 Lip GY, Frison L, Halperin JL, et al. Identifying patients at high risk for stroke despite anticoagulation: a comparison of contemporary stroke risk stratification schemes in an anticoagulated atrial fibrillation cohort. Stroke 2010;41:2731-8.

23 Amara W, Larsen TB, Sciaraffia E, et al. Patients' attitude and knowledge about oral anticoagulation therapy: results of a self-assessment survey in patients with atrial fibrillation conducted by the european Heart Rhythm Association. Europace 2016;18:151-5.

24 Joshua JK, Kakkar N. Lacunae in patient knowledge about oral anticoagulant treatment: results of a questionnaire survey. Indian J Hematol Blood Transfus 2015;31:275-80.

25 Desteghe L, Engelhard L, Raymaekers Z, et al. Knowledge gaps in patients with atrial fibrillation revealed by a new validated knowledge questionnaire. Int I Cardiol 2016;223:906-14.

26 Chenot JF, Hua TD, Abu Abed M, et al. Safety relevant knowledge of orally anticoagulated patients without self-monitoring: a baseline survey in primary care. BMC Fam Pract 2014;15:104.

27 O'Brien EC, Allen LA, Kim S, et al. Lack of patient understanding of Stroke risk and treatment strategies in those with newly diagnosed Atrial Fibrillation: a concern and an Opportunity.. 2016 https://www.dcri.org/wp-content/uploads/2016/10/SATELLITE_ Disease_Understanding_AHA_Poster.pdf (accessed 7 Mar 2017).

28 Stewart S, Ball J, Horowitz JD, et al. Standard versus atrial fibrillationspecific management strategy (SAFETY) to reduce recurrent admission and prolong survival: pragmatic, multicentre, randomised controlled trial. Lancet 2015;385:775-84

29 Hendriks JM, de Wit R, Crijns HJ, et al. Nurse-led care vs. usual care for patients with atrial fibrillation: results of a randomized trial of integrated chronic care vs. routine clinical care in ambulatory patients with atrial fibrillation. Eur Heart J 2012;33:2692-9

30 Gallagher C, Elliott AD, Wong CX, et al. Integrated care in atrial fibrillation: a systematic review and meta-analysis. Heart 2017;103:1947-53. 